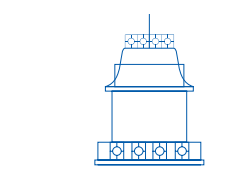

PRESENTACIÓN

\title{
¿A quién pertenece la naturaleza?
}

\author{
https://doi.org/10.17533/udea.ef.348318
}

¿A quién pertenece la naturaleza? La respuesta a esta pregunta abre el camino a múltiples investigaciones sobre la crisis civilizatoria generada por los seres humanos, de las cuales nos hacemos eco en este número. La pregunta, desde su punto de vista filosófico, cuestiona tanto nuestra comprensión como seres humanos, como los cimientos de la civilización actual, que ha creado un amplio repertorio justificatorio, a partir del cual legitima la monopolización, explotación y esclavitud de toda la naturaleza no humana. Sin duda, la estructura capitalista ha hecho de las formas de explotación actividades eficientes y violentas, con alcance global, que han generado en las distintas formas de vida en el planeta deterioro y agotamiento. Sin embargo, aparte de la debida denuncia de este aparato de generar ganancias sin límites ni condiciones, la filosofía de nuestros tiempos denuncia problemas originados por ella misma, que han contribuido a la terrible situación del siglo XXI. La negación de toda ontología propia a la naturaleza no humana; las teorías que encierran al ser humano en una burbuja llamada racionalidad, por fuera de la cual sólo estaría la nada; las éticas que desconocen todo valor no antropocéntrico; las teorías del conocimiento que desprecian la investigación de la naturaleza; todas estas son tradiciones que han de ser llamadas a juicio en nuestro siglo, para determinar su contribución a la crisis actual e iniciar la labor conjunta de hacer filosofía más allá de la especie humana.

Este esfuerzo tendrá diferentes resultados, conforme a las diferencias entre las áreas del pensamiento filosófico, y, en muchos casos, tendrá que ser una empresa interdisciplinaria.

Estudios de Filosofía se une en el número 65 al debate actual con tres investigaciones sobre el tema. Mikel Torres responde a la pregunta a partir de la consideración del sufrimiento que se genera en la naturaleza y los límites que deben existir en aquello que podemos hacer en esta. Su foco de análisis son los animales sintientes y su sufrimiento en la naturaleza, así como la obligación moral humana de acabar con este sufrimiento. El centro de la crítica de su investigación estará en las políticas medioambientales de conservación. 
Ernst-August Nuppenau, por su parte, concentra su investigación en los derechos de la naturaleza; su texto se pregunta sobre el futuro desarrollo/evolución de estos derechos y cómo integrarlos en un sistema de uso de la tierra orientado al paisaje y no al actual modelo de agricultura individual, que, entiende el autor, es un sistema puro de entrada-salida en la producción de alimentos. Así, Nuppenau usa tres narrativas de animales: los castores, los lobos y las aves. Para el autor el punto en cuestión, en comparación con el sistema actual en el que casi todos los intereses surgen de los derechos humanos, es si podemos encontrar un razonamiento ecológico para establecer derechos.

Por último, Tilo Wesche se orienta por la pregunta por la propiedad y su relación con la naturaleza. La crisis ecológica, dice el autor, ha aumentado la crítica a los derechos de propiedad, pero, debemos constatar que ni siquiera la propiedad pública ha estado en capacidad de proteger a la naturaleza de la sobre explotación y el agotamiento. Wesche propone la teoría de la propiedad sustentable, que se diferencia de las teorías comunes de la sostenibilidad del utilitarismo, el interés propio racional y la ética ambiental, que en conjunto se basan en el antropomorfismo. Esta teoría sostiene que sólo a través de su subjetividad jurídica se otorga a la naturaleza una protección intrínseca que la hace intrínsecamente digna de ser protegida; además, plantea que el poder de la libre propiedad sobre los recursos naturales está limitado por las obligaciones de sostenibilidad inherentes a la propia idea de propiedad.

En su número 67, Estudios de Filosofía seguirá publicando investigaciones sobre este tema, decisivo para la filosofía y la vida del siglo XXI; para entonces abordaremos la pregunta desde perspectivas diversas, toda vez que “¿a quién pertenece la naturaleza?" es una pregunta pertinente para muchas áreas del saber.

Bienvenidas y bienvenidos a este camino por la recomprensión del ser humano, los animales y la naturaleza.

Paula Cristina Mira Bohórquez 